\title{
EVALUATION OF COMPLICATIONS OF INTRA-PROSTATIC LOCAL ANAESTHESIA AND PERIPROSTATIC LOCAL ANAESTHESIA FOR TRUS GUIDED PROSTATE BIOPSY
}

\author{
AM ANAMUR RASHID CHOUDHURY1 ${ }^{1}$, MD.WALIUL ISLAM ${ }^{1}$, MD. GOLAM MOWLA CHOWDHURY2, \\ TASMINA PARVEEN ${ }^{3}$, PARVEEN SULTANA ${ }^{4}$ \\ ${ }^{1}$ Department of Urology, National Institute of Kidney Diseases \& Urology. ${ }^{2}$ Department of Urology, Bangabandhu Sheikh \\ Mujib Medical University, ${ }^{3}$ Department of Physiology, Uttara Adhunik Medical College, 4. Department of Forensic Medicine, \\ Enam Medical College.
}

\begin{abstract}
:
Objectives : To evaluate complications in Intra-prostatic local Anaesthesia and Periprostatic local Anaesthesia for TRUS Guided Prostate Biopsy.

Methods: This study was carried out in the Department of Urology, Bangabandhu Sheikh Mujib Medical University (BSMMU), Dhaka Medical College (DMCH) and Comfort Nursing Home, Dhaka during the period of January 2009 to October 2009, evaluate complications between periprostatic with intraprostatic local anaesthesia for transrectal prostate biopsy. For this purpose, a total number of 60 consecutive patients having increased prostate specific antigen (PSA >4.0ng/ml), abnormal DRE/transrectal ultrasound were admitted in the above mentioned hospitals were enrolled in this study for surgical management.

Result : The age ranged from 50 to 90 years and the maximum number was found in the age group of 61-70 years in both groups. The mean $( \pm S D)$ age was $68.5 \pm 7.5$ years and $70.3 \pm 8.2$ years in group I and group II respectively. No systemic lidocaine toxicity was observed in group II. But only dizziness were found in 2 cases (6.7\%) and visual disturbance were found in 1 (3.3\%) case respectively in group I. Urinary tract infection was found $2(6.7 \%)$ in group I and 1(3.3\%) in group II patients. Hematuria was found 23(76.7\%) in group I and 19(63.3\%) in group II. Rectal bleeding was found 14(46.7\%) in group I and $11(36.7 \%)$ in group II. The statistically not significant $(p>0.05)$ between two groups in chi square and fisher exact test respectively.

Conclusion : It is a simple and safe method that is less painful and it should be considered in all patients undergoing transrectal ultrasound guided prostate biopsy. Complications wer4e less in intra-prostatic local anaesthesia than periprostatic local anaesthesia for TRUS guided prostate Biopsy.
\end{abstract}

Key words: Prostate cancer, Prostate biopsy, Intraprostatic local anaesthesia, Periprostatic local anesthesia.

Bangladesh J. Urol. 2014; 17(2): 82-86

\section{Introduction:}

Transrectal ultrasound guided prostate biopsy is one of the most common procedures performed by urologists since its introduction in late 1980, TRUS guided biopsy has become a routine outpatient procedure for the diagnosis of prostate cancer. Over the past decade, one of the most significant development has been the ability

Address of Correspondence: Abdul Matin Anamur Rashid Choudhury, NIKDU, Dhaka, Email dr_choudhury2001@yahoo.com to provide local anaesthesia to patients undergoing TRUS procedure. Initially, biopsy involved taking a limited number of cores from a needle, but it has been changed with the sextant biopsy technique, which soon became the standard[1].

Despite the procedure was being well tolerated by most patients and performed without any form of anesthesia in most centers, this procedure has been reported to have a $13-90 \%$ rate of discomfort [2,3,4]. Additionally, 
the discomfort tends to become more severe with the increase in the number of cores biopsies and the prevalence of repeat biopsies[5,6]. Despite the abundance of reports in the literature regarding the evaluation of the efficacy of the Intra-prostatic local anesthesia and determination of the optimum value for number, amount and site of injection, little emphasis has been placed on complications and limitations associated with the method[7]. The vast majority of prostate cancers currently are detected by a combination of PSA screening and TRUS-guided biopsy of the prostate. Patient tolerance is a critical consideration based on the sensitivity of the prostate. Previously there was debate as to whether prostate biopsy actually causes significant discomfort for the patient, and clinicians traditionally took the biopsies with no anaesthesia[8]. Areview of published reports on prostate biopsy and anaesthesia revealed that the Intraprostatic biopsy is the most safe method [9]. The most common technique uses a basal approach, where lidocaine, under TRUS guidance, is injected directly to the prostate from apex to base.

Local anesthetic administration for TRUS-guided prostate biopsies has been extensively written by many investigators. Many studies report the benefit of local anesthetic injection. Most of them assess and report the benefit of intraprostatic local anesthetic injection evaluated the effect of intraprostatic injection with local anesthetic on the level of patient discomfort against no anesthetic injection and found that the former significantly reduced patient discomfort during the procedure $[10,11,12,13]$. In most recent studies, some investigators reported that intraprostatic local anesthetic injection significantly decreased the pain associated with prostate biopsy[14,15,16]. The use of local anesthetic to reduce patient discomfort during this procedure, as multiple recent studies have also concluded. To minimize further pain a completely new method, namely intraprostatic anesthesia and compared it with traditional periprostatic anesthesia. Better analgesia would be achieved by anesthetizing the prostate itself, which is the source of pain. Such a method would need to block all sensory nerves, not only from the posterior, but also from the anterior side. Intraprostatic administration of local anesthesia significantly decreases pain during prostate biopsy compared with periprostatic injection.

\section{Materials and Methods :}

The study was a hospital based prospective study comprises of 60 adult male patients with increased prostate specific antigen( PSA $>4.0 \mathrm{ng} / \mathrm{ml}$ ), abnormal DRE finding and abnormal transrectal ultrasound, attending in BSMMU, Dhaka Medical College Hospital and Comfort Nursing Home from January 2009 to October 2009 in the department of Urology , BSMMU. Patients were included according to selection and exclusion criteria with a target to recruit finally not less than 30 cases in each group. Grouping was done as Group I : Periprostatic L/A (30 )and Group II : Intraprostatic L/A(30). Inclusion criteria was : a) Adult male b) Increased prostate specific antigen (PSA $>4.0$ $\mathrm{ng} / \mathrm{ml}$ ) c) Abnormal DRE finding (nodule ) d) Abnormal transrectal ultrasound (hypoechoic lesion). All patients were given an explanation of the study and informed written consent was taken each patient as per instruction of the ethical committee. Patients were usually placed in the left lateral position with knees and hips flexed at $90^{\circ}$. Lidocaine gel was used with $7 \mathrm{MHZ}$ probe. The prostate was imaged in the transverse and sagital planes and prostate volume was measured by the non planimentric ellipsoid method. For periprostatic anaesthesia $5 \mathrm{ml} \mathrm{1.0 \%} \mathrm{lidocain} \mathrm{were} \mathrm{injected} \mathrm{via} 7$ inch 22 gauge PCN needle into region prostatic vascular pedicle at the base of the prostate just lateral to the junction between the prostate and seminal vesicles and for intraprostatic a total of $10 \mathrm{ml} 1.0 \%$ lidocain in portions were injected at 2 sites in the right and left sides of the prostate from base to apex[16,17]. Immediately after injections 10 core biopsies were obtained with an 18 gauge needle. After completion of the procedure patients were given a questionnaire enquiring about morbidity and pain threshold. They were asked to complete it and mail it to the urology department. Safety measure was taken to monitor ligocain toxicity.

\section{Result :}

After proper explanation of all aspects of the study, every patient was scheduled for USG - guided transrectal prostatic biopsy under local anesthesia.

Table I

Systemic lidocaine toxicity in periprostatic and intraprostatic group

\begin{tabular}{lccccc}
\hline Systemic lidocaine & \multicolumn{2}{c}{ Group I $(\mathrm{n}=30)$} & & \multicolumn{2}{c}{ Group II $(\mathrm{n}=30)$} \\
\cline { 2 - 3 } \cline { 6 - 7 } Toxicity & $\mathrm{n}$ & $\%$ & & $\mathrm{n}$ & $\%$ \\
\hline Lidocaine allergy & 0 & 0.0 & & 0 & 0.0 \\
Hypotension & 0 & 0.0 & & 0 & 0.0 \\
Anaphylactic reaction & 0 & 0.0 & & 0 & 0.0 \\
Dizziness & 2 & 6.7 & & 0 & 0.0 \\
Visual disturbance & 1 & 3.3 & & 0 & 0.0 \\
\hline
\end{tabular}

Group I: Periprostatic

Group II: Intraprostatic

Table - I showed that the no systemic lidocaine toxicity was observed in group II. But only dizziness were found in 2 cases (6.7\%) and visual disturbance were found in $1(3.3 \%)$ case respectively in group I. 
Table II

Complications in periprostatic and intraprostatic groups

\begin{tabular}{lccccc}
\hline Complications & \multicolumn{7}{c}{ Group I $(\mathrm{n}=30)$} & Group II $(\mathrm{n}=30)$ & $\mathrm{P}$ \\
& $\mathrm{N}$ & $\%$ & $\mathrm{n}$ & $\%$ & Value \\
\hline $\begin{array}{l}\text { Urinary tract infection } \\
\quad \text { Yes }\end{array}$ & 2 & 6.7 & 1 & 3.3 & $\mathrm{~b} 0.500$ \\
$\quad$ No & 28 & 93.3 & 29 & 96.7 & \\
$\begin{array}{l}\text { Hematuria } \\
\text { Yes }\end{array}$ & & & & & \\
$\quad$ No & 7 & 76.7 & 19 & 63.3 & $\mathrm{a} 0.259$ \\
Rectal bleeding & 23.3 & 11 & 36.7 & \\
$\quad$ Yes & 14 & 46.7 & 11 & 36.7 & $\mathrm{a} 0.432$ \\
$\quad$ No & 16 & 53.3 & 19 & 63.3 & \\
\hline
\end{tabular}

Group I: Periprostatic Group II: Intraprostatic ${ }^{a}=p$ value reached from chi square test $b=p$ value reached from fisher exact test

Regarding the complications the table- II showed urinary tract infection was found $2(6.7 \%)$ in group I and $1(3.3 \%)$ in group II patients. Hematuria was found $23(76.7 \%)$ in group I and 19(63.3\%) in group II. Rectal bleeding was found $14(46.7 \%)$ in group I and $11(36.7 \%)$ in group II. The statistically not significant $(p>0.05)$ between two groups in chi square and fisher exact test respectively.

\section{Discussion :}

TRUS-guided biopsy of the prostate has become a ubiquitous and critical tool for evaluating and managing prostate cancer. Improving patient tolerance and comfort associated with the procedure, by decreasing associated pain and morbidity, is therefore of paramount importance. Regarding the complications of biopsy procedure a study showed that rectal bleeding was more than urinary tract infection in their series $[28,29,30,31]$. In a current study urinary tract infection, hematuria were found less in a group which were given intraprostaic anaesthesia during TRUS[10,32,33,34].

Regarding lidocaine toxicity, it was observed that lidocaine allergy, hypotension and anaphylactic reaction were not found in both groups. However, dizziness and visual disturbance were found $1(3.3 \%)$ and $1(3.3 \%)$ in group I and group II respectively. As regards to the systemic lidocaine toxicity, a number of investigators studied $2.0 \%$ in their studies[18]. Regarding the complications biopsy procedure the present study showed that rectal bleeding and urinary tract infection were observed 2(6.7\%) and 1(3.3\%) in group I and group II respectively. The same complication were found in $2 \%$ of case in the study in their series $[3,19,20,21]$ In the current study urinary tract infection was $2(6.7 \%)$ in group I and 1(3.3\%) in in group II. Regarding the hematuria, there are other studies have shown in a prospective study that having $63.0 \%$ and $75.0 \%$ in group I and group II respectively, which are consistent to the present study, where the present study found hematuria $23(76.7 \%)$ in group I and 19(63.3\%) in group II. Similar results obtained by some investigators in their study[3,12]. In this study it was observed that Rectal bleeding was $14(46.7 \%)$ in group I and $11(36.7 \%)$ in group II. Similar findings were found [12].

\section{Conclusion:}

This prospective study was carried out to assess systemic lidocaine toxicity and complications between periprostatic with intraprostatic local anaesthesia for transrectal prostate biopsy. TRUS-guided biopsy of the prostate has become a ubiquitous and critical tool for evaluating and managing prostate cancer. Complications were less in intra-prostatic local anaesthesia in comparison to periprostatic local anaesthesia for TRUS guided prostate biopsy. Intraprostatic local anesthesia technique is more acceptable technique for prostate biopsy. It is a simple and safe method that is less painful and it should be considered in all patients undergoing transrectal ultrasound guided prostate biopsy.

\section{Conflict of Interest: None declared}

\section{References:}

1. Hodge KK, McNeal JE, Terris MK. Random systematic versus directed ultrasound guided transrectal core biopsies of the prostate.J Urol .1989;142:71.

2. Clements R, Aideyan OU, Griffiths GJ. Side effects and patient acceptability of transrectal biopsy of the prostate. Clin Radiol .1993;47:125.

3. Desgrandchamps F, Meria P, Irani J, Desgrippes A, Teillac P, Le Duc A. The rectal administration of lidocaine gel and tolerance of transrectal ultrasonography guided biopsy of the prostate: a prospective randomized placebo controlled study. BJU Int .1999; 83:1007-1009.

4. Crundwell MC, Cooke RW, Wallace DM. Patients' tolerance of transrectal ultrasound guided prostate biopsy: an audit of 104 cases. BJU Int.1999; 83:792-795.

5. Rodriguez A, Kyriakou G, Leray E, Lobel E, Guille F. Prospective study comparing two methods of anesthesia for prostate biopsies: Apex periprostatic nerve block versus intrarectal lidocaine gel: review of literature. Eur Urol .2003; 44:195-200. 
6. Soloway MS, Obek C. Perprostatic local anaesthesia before ultrasound guided prostate biopsy. J urol. 2000; 163:172.

7. Taverna G, Maffezzini M, Benetti A, Seveso M , Guisti G , Graziotti P . A single injection of lidocaine as local anesthetic for ultrasonoguided needle biopsy of the prostate. J Urol. 2002; 167:222-23.

8. Irani J, Fournier F, Bon D, Gremmo E, Dore B, Aubert J.Patient tolerance of transrectal ultrasoundguided biopsy of the prostate. Br J Urol.1997; 79:608-610.

9. Aus G, Damber J, Hugosson J. Prostate biopsy and anaesthesia: an overview. Scand J Urol Nephrol .2005; 39:124-129.

10. Mutaguchi K, Shinohara K, Matsubara A, Yasumoto H, Mita K, Usui T. Local anesthesia during 10 core biopsy of the prostate: comparison of 2 methods. The Journal of Urology .2005; 173:742-745.

11. Berger AP, Frauscher F, Halpern EJ, Spranger R, Steiner H. Bartsch G. Periprostatic administration of local anesthesia during transrectal ultrasoundguided biopsy of the prostate: a randomized, double-blind, placebo-controlled study. Urology .2003; 61: 585-588.

12. Ozden E, Yaman O, Gogus C, Ozgencil E, Soygur $\mathrm{T}$. The optimum doses of and injection locations for periprostatic nerve blockade for transrectal ultrasound guided biopsy of the prostate: a prospective, randomized, placebo controlled study. J Urol.2003; 170:2319-2322.

13. Walsh K, O'Brien1 T, Salemmi1 A, Popert R. (2003). A randomised trial of periprostatic local anaesthetic for transrectal biopsy. Prostate Cancer and Prostatic Diseases.2003; 6: 242-244.

14. Wu C.L, Carter H.B, Naqibuddin M, Fleisher LA. Effect of local anesthetics on patient recovery after transrectal biopsy. Urology .2001; 57: 925-29.

15. Walker AE, Schelvan C, Rockall AG, Rickards D, Kellett MJ. Does pericapsular lignocaine reduce pain during transrectal ultrasonography-guided biopsy of the prostate? BJU Int. 2002; 90: 883886.

16. Matlaga BR, Lovato JF, Hall MC. Randomized prospective trial of a novel local anesthetic technique for extensive prostate biopsy.Urology .2003;61: 972-976.
17. Crater HB, Partin AW. Diagnosis and staging of prostate cancer. In: Walsh Patrick C, Retilk Alan B, E Darracott Vaughan, Alan J Wein (editors): Campbell's Urology, $8^{\text {th }}$ edition, Philadelphia: Saunders.2002; pp. 3055-3064.

18. Change JJ, Shinohara K, Presti JC. Prospective evaluation of lateral biopsies of the peripheral zone for prostate cancer detection. The journal of Urology.1998; 160: 2111-2114.

19. Epstein Jl. Pathology of prostatic neoplasia. In: Walsh Patrick C, Retik Alan B, E Darracott Vaughan, Alan J Wein .editors. Campbell's Urology, $8^{\text {th }}$ ed, Philadelphia: Saunders .2002; pp. 3025-3037.

20. Applewhite JC, Matlaga BR, Hall C. Transrectal ultrasound and biopsy in the early diagnosis of prostate cancer. Cancer.2001; 8 :141-150.

21. Lilja H. A kallikrein-like serine protease in prostatic fluid cleaves the predominant seminal vesical protein. J Clin Invest.1985; 76: pp.1899.

22. Terris MK. In: Walsh Patrick $C$, RetikAB, Vaughan ED, Wein AJ editors. Ultrasonography and biopsy of the prostate $.8^{\text {th }}$ edition. Campbell's Urology .Philadelphia:Saunders;2002. pp. 3038-3054.

23. Carroll P, Shinohara K. Transrectal ultrasound guided prostate biopsy. J Urol vol. 1999; 164: 203207.

24. Shinohara K. Evolution of prostate biopsy. Prostate Update .1999; 4:123-126.

25. Schostak M, Christoph F, Muller M, Heicappell R, GoessI G, Staehler M.Optimizing local anesthesia during 10-core Biopsy of the prostate. Urology.2002; 60:253-257

26. Adsan O, Inal G, Ozdogan L, Kaygisiz O, Ugurlu $O$, Cetinkaya M. Unilateral pudendal nerve blockade for relief of all pain during transrectal ultrasound-guided biopsy of the prostate: a randomized, double blind, placebo-controlled study. Urology .2004; 64:528-531.

27. Naughton CK, Ornstein DK, Smith DS, Catalona WJ. Pain and morbidity of transrectal ultrasound guided prostate biopsy: a prospective randomized trial of 6 versus 12 cores. The Journal of Urology.2000; 163:168-171.

28. Choudhury AR, Chowdhury GM, Rahman MS. Comparative study on periprostatic local anesthesia with intraprostatic local anesthesia for 
ultrasonoguided transrectal prostatic biopsy. Thesis. BSMMU. 2009; 53.

29. TurgutAT, Olcucuoglu E, Kosar P, Geyik PO, Kosar $U$. Complications and Limitations Related to Periprostatic Local Anesthesia before TRUSGuided Prostate Biopsy. J Clin Ultrasound 2008; 36: 67-71.

30. Manseck A, Guhir K, Froehner M. Morbidity and discomfort of ten-core biopsy of the prostate evaluated by quest-discomfort of the prostate evaluated by questionnaire. Urol Int .2001; 66: 197200.

31. Djavan B, Waldert M, Zlotta A. Safety and morbidity of first and repeat transrectal ultrasound guided prostate needle biopsies: results of a prospective European prostate cancer detection study. J Urol .2001;166: 856-860.
32. Peyromaure M, Ravery V, Messas A. Pain and morbidity of an extensive prostate 10-biopsy protocol: a prospective study in 289 patients. J Urol .2002; 160:218-221.

33. Raaijmakers R, Kirkels WJ, Roobol MJ, Wildhagen ME. Complication rates and risk factors of 5802 transrectal ultrasound-guided sextant biopsies of the prostate within a population-based screening program. Urology.2002; 60:826-830.

34. Choudhury AR ,Parveen T. Periprostatic Local Anesthesia Vs Intraprostatic Local Anaesthesia for Ultrasono guided Transrectal prostatic BiopsyComprehensive Literature Review. J Uttara Adhunik Med Coll.2012; 2(1):44-49.

Abbreviations:

DRE : Digital Rectal Examination

PSA : Prostate Specific Antigen

TRUS : Transrectal ultrasound 